\title{
Return to work following arthroscopic supraspinatus repair: A survey of UK practice
}

\author{
Jayanti Rai ${ }^{*}$, Jaleel Mohammed ${ }^{2}$ and Ian Swaine ${ }^{3}$ \\ ${ }^{1}$ Maidstone \& Tunbridge Wells NHS Trust, Maidstone, United Kingdom \\ ${ }^{2}$ Physical Therapy Association for Graft Versus Host Disease, Swindon, United Kingdom \\ ${ }^{3}$ University of Greenwich, Sports Science, Medway, United Kingdom
}

\begin{abstract}
Objective: The primary objective was to explore current practice and advice given to patients about a return to work (RTW) following arthroscopic supraspinatus repair (single tendon) by the patients surgeon and physiotherapist.

The secondary objective was to explore the consensus on key predictive factors for successful phased and full return to work following arthroscopic supraspinatus repair surgery.

Methods: An online electronic anonymous survey was developed and hosted by survey monkey to capture pertinent information relating to the return to work postoperatively.

The survey was approved by British Elbow and Shoulder Society (BESS) research committee in 2017. The survey link was disseminated via email to expert shoulder surgeons and physiotherapist who are BESS members. Survey had a vignette with different age group, tear size, type of work and return to work advice. Consistency of responses and thereby the internal validity of the questionnaire was tested via a correlation analysis between responses. Results were comparatively analysed with Mann-Whitney U test and Chi-square tests.

Results: Sixty-two valid responses were received (48 surgeons; 14 physiotherapists). Regarding RTW time frames, a wide range of responses was received (sedentary work 0-12 weeks, light manual workers 2-24 weeks, and manual workers 3-36 weeks). Furthermore, responses varied among professionals ( $\mathrm{P}=0.01)$. The range of motion of the operated shoulder, functional shoulder scores, self-reported patient scores and patient expectations were considered moderate to very important predictive factors for successful full RTW arthroscopic supraspinatus repair surgery. Pain, psychological profile, job satisfaction, and patient compliance were also considered relevant. 77\% respondents said they liaise with occupational health departments and patient's general practitioners with regards to their patient's RTW.

Conclusion: This is the first survey in the UK exploring current practices with regards to RTW after arthroscopic supraspinatus repair. Responses highlight variability in the advice given to the patients on phased and full return to work by the professionals even for a single tendon repair. There is a need to standardise the advice given to patients and further research is needed with patient public involvement to develop an evidenced-based guideline for RTW.

Implications: Return to work is influenced by a combination of factors. The relationship between each of these needs to be explored in greater depth and wider understanding of the variables influencing the patient's RTW following arthroscopic supraspinatus repair.
\end{abstract}

\section{Introduction}

Shoulder pain is one of the most common cause of reduced functional incapacity affecting the activities of daily life and work [1]. Although pain related to shoulder ranks number three among musculoskeletal conditions [2], its prevalence is on the rise [3], not only in the UK but also in many western countries [4,5]. Despite the growing incidence, there is no gold standard treatment yet, which would help completely address shoulder pain. This is due to the complex matrix of structures that are directly and indirectly involved in its function and multiaxial motion [6]. There has always been a debate on surgical versus conservative management for rotator cuff pathology [7-9]. Furthermore, a large variation among the surgeons regarding the type of surgery itself for the same pathology [10] has meant different recovery and return to activity periods.

Although rotator cuff pathology is linked to several causative and trigger factors, it is a common occurrence among employees who are engaged in repetitive overhead work [11] and also among certain sports' populations that involve overhead activity $[12,13]$. Work-related upper limb disorders (WRULDs) accounted for round 3.9 million working days lost in the UK in 2016/17 [14]. RTW criteria for Size of the rotator cuff tear, open versus mini versus arthroscopic procedure, and surgeon's own preference on the duration of immobilization, the healing time required for the patient, are some of the many factors which can influence patient's functional gains and return to work [1517], the relative advantage or disadvantage of early mobilization of the shoulder compared with immobilization post rotator cuff surgery [18] has been a topic of debate and trials are still being conducted to find the ideal immobilisation period to allow healing postoperatively [19].

${ }^{*}$ Correspondence to: Jayanti Rai, Maidstone \& Tunbridge Wells NHS Trust, Maidstone, United Kingdom, E-mail: jphysio@gmail.com

Key words: arthroscopic supraspinatus repair, return to work, predictive factors

Received: August 02, 2020; Accepted: August 11, 2020; Published: August 20, 2020 
Although return to work is a complex process which needs to take into account the patients expectations and perception of functional capacity post-surgery, psychological factors, work environment and demands and calculating the amount of stress the tissue can manage (graded return to work) [20], some studies has demonstrated that the personal opinion of the surgeon or a healthcare professional on when the patient is fit to return to work usually takes a precedence and can influence return to work $[21,22]$.

Considering the vital role surgeons and a physiotherapists (PT) can play in the RTW recommendation post rotator cuff surgery, the primary objective of this study was to explore current UK practice and advice given to patients about a return to work (RTW) following arthroscopic supraspinatus repair (single tendon) by surgeons and PTs.

\section{Aims of Survey}

1. To determine current UK practice with respect to RTW after RC repair.

2. To identify predicative factors associated with rates of RTW after $\mathrm{RC}$ repair.

3. To determine what objective measures could be used in practice to guide RTW after RC repair.

4. To examine if surgeon and PT practice varies regarding RTW after $\mathrm{RC}$ repair in practice.

5. To see if consensus could be reached regarding RTW after RC repair guidelines.

\section{Methodology}

\section{Participants}

Expert shoulder surgeons and physiotherapists who are members of British Elbow \& Shoulder Society (BESS) were anonymously surveyed regarding their current practice on return to work following an arthroscopic supraspinatus repair.

\section{Data collection}

An online survey was be developed by the author with help of BESS. It was hosted by Survey Monkey (https://www.surveymonkey. com) to capture pertinent information relating to the return to work post operatively (Appendix 1). A link to the survey was sent by email to the BESS members. Members were given case scenarios and requested to use their clinical expertise to answer the questions.

\section{Data analysis}

Descriptive summary statistics were generated by Survey Monkey and subsequently imported into Excel to facilitate the data reporting in terms of period of immobilisation, load permitted, and time taken to return to work.

Based on the response rate to the survey, data was further partition into the responses from subgroups (i.e. different professions) and comparative statistical analysis was undertaken.

\section{Statistical methods}

The first set of analyses summarised the results of the survey for all respondents combined. Additionally, separate responses were given for physiotherapists and for surgeons. A statistical comparison of the differences between surgeons for all questionnaire responses was made.
Several questions on the survey were ordinal in nature. These questions were compared between groups using the Mann-Whitney tests. Other questions had answers that were potentially continuous in nature. The data from all such questions was found to have positively skewed distributions, and so the Mann-Whitney test was used for the analyses of these questions as well. Categorical variables were compared between categories using Fishers exact test.

A second set of analyses compared suggested immobilisation times between patients of two different ages. As each respondent gave a response for both ages, the data was paired in nature. Due to ordinal nature of the outcome scale, the Wilcoxon matched-pairs test was used for the analyses.

\section{Results}

A total of $8.27 \%$ of total BESS members responded (62/750) out of which $10 \%$ of BESS PT responded (14/140) and $8.6 \%$ of BESS surgeons responded (48/560). The data collected from 62 respondents was analysed in following way:

1. If respondents gave a range of values for RTW the earliest date was selected,

2. If respondents gave a range of values for FU the latest date was selected,

3. The data collected relating to whether special orthopaedic tests were predictive of RTW was qualitatively analysed.

\section{Data summaries and comparison between professions}

The first analyses summarised the survey responses, both for all respondents, and separately by profession (Table 1). A summary of the survey results for all, and by profession, is given in the next two tables. Continuous and ordinal variables were summarised by either the mean and standard deviation, or the median and inter-quartile range, as thought to be most appropriate for each question. Categorical variables are summarised by the number and percentage in each category. The final column reports the p-values from comparisons of the responses given by PT's and surgeons.

The majority of clinicians were UK based. For all respondents combined, tissue quality and tendon traction were thought to be the most relevant, as these had the highest average scores. Tear size was the least relevant with the lowest average score. Surgeons scored both tissue quality and tendon traction as more relevant than physios, with significant higher scores for these items. Conversely, biceps treatment was rated significantly more relevant by physios than by surgeons.

Immobilisation times scored approximately the same for all cases, with averages scores all between 4 and 5.5 out of 7 . Surgeons suggested significantly longer times for the scenarios where the patient had a $<5 \mathrm{~cm}$ supraspinatus plus infraspinatus tear.

\section{Return to work}

The time to return to work was longer for heavy manual workers than for sedentary and light manual works (Table 1A). Surgeons suggested a significantly longer time to return to work, with a median of 12 weeks, compared to a median of 8 weeks suggested by the PT's. Surgeons also suggested a significantly longer return to sports for both non-contact and contact sports. Conversely, surgeons suggested shorter returns to driving than physios, although the results for the operated left arm did not quite reach statistical significance. Around three-quarters of respondents suggested a liaison with occupational health, and that the patient's GP should be informed; however, the author has never experienced this in their own clinical practice. 
Table 1. The first table summarises the results for the first half of the survey. Summary statistics are mean \pm standard deviation, or number (percentage)

\begin{tabular}{|l|c|c|c|c|}
\hline Variable & $\begin{array}{c}\text { All } \\
(\mathbf{n = 6 2})\end{array}$ & $\begin{array}{c}\text { Physios } \\
(\mathbf{n = 1 5})\end{array}$ & $\begin{array}{c}\text { Surgeons } \\
(\mathbf{n = 4 7 )}\end{array}$ & P-value \\
\hline UK based & $60(97 \%)$ & $15(100 \%)$ & $45(96 \%)$ & 1 \\
\hline Immobilisation factors (+) & $1.6 \pm 0.5$ & $1.5 \pm 0.5$ & $1.7 \pm 0.5$ & 0.14 \\
\hline Tear size & $3.8 \pm 1.1$ & $3.3 \pm 0.9$ & $4.0 \pm 1.1$ & 0.02 \\
\hline Tissue quality & $3.7 \pm 1.2$ & $3.2 \pm 1.0$ & $3.9 \pm 1.2$ & 0.02 \\
\hline Tendon traction & $2.1 \pm 1.1$ & $3.1 \pm 1.0$ & $1.8 \pm 1.1$ & $<0.001$ \\
\hline Arm dominance & $2.1 \pm 1.2$ & $3.2 \pm 0.7$ & $1.8 \pm 1.1$ & $<0.001$ \\
\hline Biceps treatment & $3.2 \pm 1.4$ & $3.1 \pm 1.1$ & $3.2 \pm 1.5$ & 0.72 \\
\hline Surgery type & $3.1 \pm 1.3$ & $3.4 \pm 0.8$ & $3.0 \pm 1.4$ & 0.61 \\
\hline Healing rate & $2.5 \pm 1.2$ & $2.9 \pm 0.9$ & $2.5 \pm 1.2$ & 0.24 \\
\hline Pain & & & & \\
\hline Immobilisation time (++) & $4.5 \pm 1.4$ & $4.8 \pm 1.5$ & $4.4 \pm 1.4$ & 0.33 \\
\hline Age 60, 3cm Sup ear & $5.0 \pm 1.1$ & $4.7 \pm 1.5$ & $5.1 \pm 1.3$ & 0.27 \\
\hline Age 60, 3-5cm Sup Tear & $5.4 \pm 1.2$ & $4.7 \pm 1.6$ & $5.6 \pm 0.9$ & 0.02 \\
\hline Age 60, <5cm Sup + Inf & $4.4 \pm 1.4$ & $4.3 \pm 1.6$ & $4.4 \pm 1.4$ & 0.91 \\
\hline Age 45, 3cm Sup ear & $5.0 \pm 1.6$ & $4.9 \pm 1.6$ & $5.0 \pm 1.3$ & 0.94 \\
\hline Age 45, 3-5cm Sup Tear & $5.3 \pm 1.3$ & $4.5 \pm 1.7$ & $5.5 \pm 1.2$ & 0.02 \\
\hline Age 45, <5cm Sup + Inf & & & \\
\hline & & & \\
\hline
\end{tabular}

$(+)$ Scored on scale from: $1=$ not relevant to $5=$ very relevant, $(++)$ Scored on scale from: $0=$ shortest time to $7=$ longest time

Table 1A. The results for the second half of the survey. Summary statistics are mean \pm standard deviation, median [inter-quartile range], or number (percentage).

\begin{tabular}{|c|c|c|c|c|}
\hline Variable & $\begin{array}{c}\text { All } \\
(n=62)\end{array}$ & $\begin{array}{c}\text { Physios } \\
(n=15)\end{array}$ & $\begin{array}{c}\text { Surgeons } \\
(n=47)\end{array}$ & P-value \\
\hline \multicolumn{5}{|l|}{ Return to work (wks) } \\
\hline Sedentary worker & $6[4,6]$ & $6[4,6]$ & $4[2,6]$ & 0.25 \\
\hline Light manual worker & $6[6,10]$ & $6[4,12]$ & $8[6,10]$ & 0.66 \\
\hline Heavy manual worker & $12[8,12]$ & $8[6,12]$ & $12[12,12]$ & 0.02 \\
\hline \multicolumn{5}{|l|}{ Return to driving (wks) } \\
\hline Right arm op & $6[6,8]$ & $12[6,12]$ & $6[6,8]$ & 0.04 \\
\hline Left arm op & $8[6,8]$ & $12[6,12]$ & $8[6,8]$ & 0.08 \\
\hline \multicolumn{5}{|l|}{ Return to sports (wks) } \\
\hline Non-contact & $12[12,12]$ & $12[8,12]$ & $12[12,20]$ & 0.03 \\
\hline Contact & $20[12,24]$ & $12[12,20]$ & $24[20,24]$ & 0.003 \\
\hline Liaise with occ health & $47 / 60(78 \%)$ & $10 / 13(77 \%)$ & $37 / 47(79 \%)$ & 1 \\
\hline Inform patient's GP & $44 / 60(73 \%)$ & $7 / 13(54 \%)$ & $37 / 47(79 \%)$ & 0.09 \\
\hline No fixed length FU $\left(^{*}\right)$ & $4 / 58(7 \%)$ & $1 / 11(9 \%)$ & $3 / 47(6 \%)$ & 1 \\
\hline Length FU (wks) $(* *)$ & $24[12,52]$ & $38[12,52]$ & $24[12,25]$ & 0.46 \\
\hline \multicolumn{5}{|l|}{ Return work success $(+)$} \\
\hline Range motion & $3.8 \pm 1.0$ & $3.7 \pm 0.8$ & $3.9 \pm 1.0$ & 0.29 \\
\hline Radiological evidence & $2.0 \pm 1.3$ & $2.8 \pm 1.3$ & $1.8 \pm 1.3$ & 0.01 \\
\hline Patient self-report & $4.4 \pm 0.7$ & $4.1 \pm 1.0$ & $4.5 \pm 0.7$ & 0.2 \\
\hline Patient expectation & $4.0 \pm 0.8$ & $3.9 \pm 1.0$ & $4.0 \pm 0.7$ & 0.61 \\
\hline
\end{tabular}

$(+)$ Scored on scale from: $1=$ not relevant to $5=$ very relevant $(*)$ Patients not indicating a fixed length of follow-up indicated that follow-up time should be vary depending on patient needs (**) Figures based on those who indicated a specific time period.

Neither variable varied significantly between the two professions. A minority of respondents (7\%) felt that no fixed length of follow-up should be given, with this varying depending on the patient. Of those who did give a fixed length, the median follow-up was 24 weeks. The highest scores for return to work success were patient self-report of their return, and patient expectations. Neither of these factors varied between professions. Of the other measures, radiological evidence was rated as more relevant by physios than by surgeons

\section{Immobilisation times between ages}

The second set of analyses compared the differences in recommended immobilisation times between male patients of different ages with similar tears. The results are summarised in table 2 . The figures are the mean and standard deviation score (on a scale from 0-7) for each age group, along with p-values indicating the significance of the differences.

The analysis suggested no strong evidence of a difference in the immobilisation times between males of different ages in any of the three situations. There was slight evidence of a difference for the $3 \mathrm{~cm}$ supraspinatus tear, but the result was quite significant and there was little difference in mean values between the age groups.

\section{Gender}

Immobilisation periods after arthroscopic repair was ranked significantly different between professions $(\mathrm{p}=0.01)$ where $85 \%$ of the surgeons considered it as 'not relevant'. However, within the PT's, $35 \%$ believed it as not relevant but $29 \%$ of the therapists leaned towards being relevant in the recovery process.

\section{Pre-operative tissue quality}

A significant difference between the therapist and the surgeons opinion was found on the correlation between the pre-operative tissue quality and immobilization period $(\mathrm{p}=0.01)$. Surgeons considered it to be moderately (21\%) to increasingly (36\%) to very relevant $(36 \%)$ and PT considered it slightly relvant (23\%) to moderately relvant $(38 \%)$ to increasing relvant (38\%). None of the therapists ranked it as very relevant.

\section{Amount of tendon retraction}

A significant difference between the therapist and the surgeons' opinion was found on the correlation between the amount of tendon retraction and the immobilization period $(\mathrm{p}=0.01)$. Surgeons considered it to of increased relevance (36\%) to very relvant $(36 \%)$. Physiotherapists considered it moderately relvant (42\%) to increasing relvant (35\%). None of the therapists ranked it as very relevant.

\section{Smoking}

No significant difference in ranking between professions $(\mathrm{p}=0.19)$ was found for smoking status and immobilisation periods post arthroscopic repair.

\section{Arm dominance}

A significant difference between the therapist and the surgeons' opinion was found on the correlation between the arm dominance and the immobilization period $(\mathrm{p}=0.01)$. Surgeons considered it to be not relevant (53\%) or slightly relvant (26\%). Whereas physiotherapists considered arm dominance to be moderate (43\%) to increasingly relevant (36\%).

\section{Involvement of biceps pathology}

A significanlt difference between the therapist and the surgeons' opinion was found on the correlation between the involvement of biceps pathology and the immobilization period $(\mathrm{p}=0.01)$. Surgeons considered it to of no relevance (61\%) and PTconsidered it moderately relvant (57\%).

Table 2. Immobilization times by age and extent of tear

\begin{tabular}{|l|c|c|c|}
\hline Type of tear & $\begin{array}{c}\text { Age 60 } \\
\text { Mean } \pm \text { SD }\end{array}$ & $\begin{array}{c}\text { Age 45 } \\
\text { Mean } \pm \text { SD }\end{array}$ & P-value \\
\hline $3 \mathrm{~cm}$ supraspinatus tear & $4.5 \pm 1.4$ & $4.4 \pm 1.4$ & 0.05 \\
\hline $3-5 \mathrm{~cm}$ supraspinatus tear & $5.0 \pm 1.1$ & $5.0 \pm 1.6$ & 0.97 \\
\hline$<5 \mathrm{~cm}$ supraspinatus + infraspinatus tear & $5.4 \pm 1.2$ & $5.3 \pm 1.3$ & 0.31 \\
\hline
\end{tabular}




\section{Type of surgery}

No significant difference $(\mathrm{p}=0.63)$ in ranking between professions were found for the type of surgery considering immobilization periods after the arthroscopic repair.

\section{Tendon healing rate}

No significant difference $(\mathrm{p}=0.73$ ) in ranking for immobilisation and tendon healing rate was found between professions.

\section{Pain}

No significant difference $(\mathrm{p}=0.24)$ in ranking for pain and immobilizations was found between the therapist and the surgeons.

\section{Other factors which can influence the opinion for immobilization}

Other factors that were reported via free text in the survey which could influence the period of immobilisation: patient compliance; revision surgery; use of augmentation; shape of the tear; and the quality of the bone for anchor.

\section{Answers based on case scenarios} given:

a) How long would BESS members immobilise in a sling the cases

- All non-smoking males, and the dominant arm is operated on.

- The repair is considered to be stable and done by margin convergence with no concurrent pathology.

- In addition, does the response vary according to profession?

Note on the bar graph (Figure 1) the significant difference between $\mathrm{PT}$ and surgeons when recommending period of immobilisation for the patient group 60 years with a $5 \mathrm{~cm}$ or more tear and 2 tendons involved and for a patient aged 45 years of age with the same criteria. It is notable that the surgeons would immobilise for a longer period ( $6 \pm 1$ weeks) than the physiotherapists ( $5 \pm 2$ weeks) in the 60 -year-old patient (Tables 3 and 4 ). In the 45 -year-old patient surgeons would immobilise for longer too $(5 \pm 1$ weeks $)$ and physiotherapists a shorter period ( $4 \pm 2$ weeks).

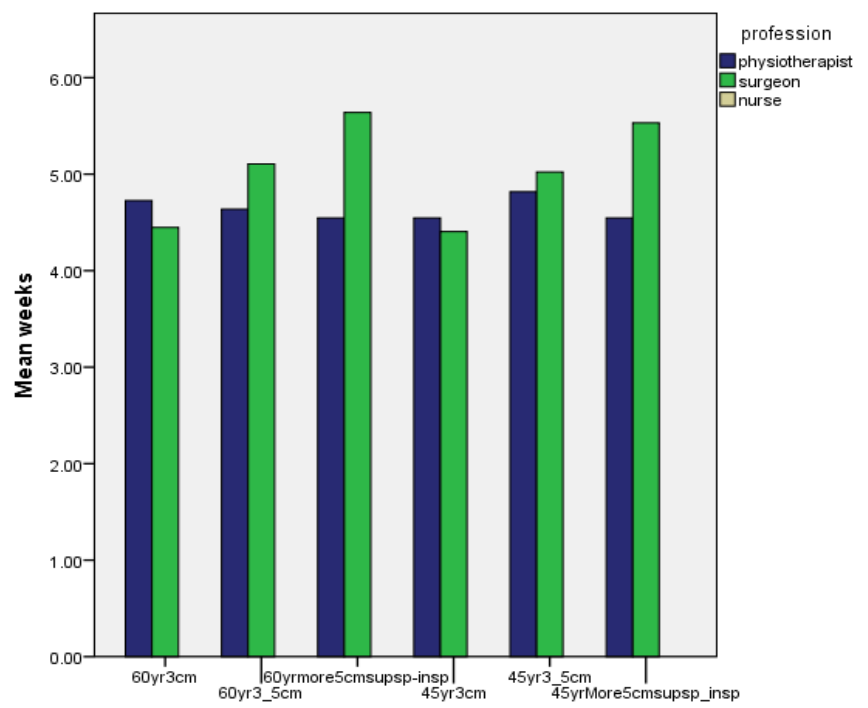

Figure 1. Difference between the surgeons and physiotherapists on immobilization periods.
Table 3. Descriptive Statistics. Time frame in weeks for immobilsation and return to activity for combined professions.

\begin{tabular}{|l|c|c|c|c|c|}
\hline & $\begin{array}{c}\text { Min } \\
\text { weeks }\end{array}$ & $\begin{array}{c}\text { Max } \\
\text { weeks }\end{array}$ & $\begin{array}{c}\text { Mean } \\
\text { weeks }\end{array}$ & $\begin{array}{c}\text { STD } \\
\text { weeks }\end{array}$ & $\begin{array}{c}\text { Sig diff } \\
\text { between } \\
\text { professions } \\
\text { p value }\end{array}$ \\
\hline $60 \mathrm{yr} / 3 \mathrm{~cm}$ tear & 1 & 6 & 4 & 1 & 0.46 \\
\hline $60 \mathrm{yr} / 3-5 \mathrm{~cm}$ tear & 1 & 6 & 5 & 1 & 0.18 \\
\hline $60 \mathrm{yr} />5 \mathrm{~cm}$ tear/SS+IS & 1 & 7 & 5 & 1 & $0.02^{*}$ \\
\hline $45 \mathrm{yr} / 3 \mathrm{~cm}$ tear & 1 & 6 & 4 & 1 & 0.91 \\
\hline $45 \mathrm{yr} / 3-5 \mathrm{~cm}$ tear & 1 & 7 & 5 & 1 & 0.94 \\
\hline $45 \mathrm{yr} />5 \mathrm{~cm}$ tear/SS+IS & 1 & 7 & 5 & 1 & $0.02^{*}$ \\
\hline Sedentary worker RTW & 0 & 12 & 5 & 3 & 0.23 \\
\hline Light manual worker RTW & 2 & 24 & 8 & 4 & 0.88 \\
\hline Manual worker RTW & 3 & 36 & 12 & 5 & $0.01^{*}$ \\
\hline RT Drive/right side operated & 3 & 12 & 7 & 2 & 0.05 \\
\hline RT Drive/left side operated & 3 & 12 & 7 & 2 & 0.07 \\
\hline RT to non-contact sport & 2 & 28 & 14 & 5 & $0.03^{*}$ \\
\hline RT to contact sport & 6 & 40 & 20 & 7 & $0.01^{*}$ \\
\hline Follow up & 4 & 72 & 27 & 17 & 0.25 \\
\hline
\end{tabular}

$\mathrm{PH}=$ physiotherapist, $\mathrm{SX}=$ surgeon; $\quad *=$ significant difference between professions; $\mathrm{SS}=$ supraspinatus; $\mathrm{IS}=$ infraspinatus; $\mathrm{RT}=$ return to; $\mathrm{RTW}=$ return to work; $\mathrm{yr}=$ years old.

Table 4. Differences in time frames cited between professions

\begin{tabular}{|l|c|c|c|}
\hline & Profession & Mean weeks & Std. weeks \\
\hline \multirow{2}{*}{$60 \mathrm{yr} />5 \mathrm{~cm}$ tear/SS+IS } & physiotherapist & 5 & 2 \\
\cline { 2 - 4 } & surgeon & 6 & 1 \\
\hline \multirow{2}{*}{$45 \mathrm{yr} />5 \mathrm{~cm}$ tear/SS+IS } & physiotherapist & 4 & 2 \\
\cline { 2 - 4 } & surgeon & 5 & 1 \\
\hline \multirow{2}{*}{ RTW manual worker } & physiotherapist & 9 & 3 \\
\cline { 2 - 4 } & surgeon & 12 & 3 \\
\hline \multirow{2}{*}{ RT to non-contact sport } & physiotherapist & 10 & 5 \\
\hline \multirow{2}{*}{ RT to contact sport } & surgeon & 14 & 7 \\
\hline
\end{tabular}

The above bar graph illustrates the significant differences between physiotherapists and surgeons when considering return to work for a manual worked and RT Sport with physiotherapists suggesting significantly shorter time frames for each of these activities compared to surgeons (Table 4). It is notable that RT manual work differs by 3 weeks, RT non-contact sport by 2 weeks and RT contact sport by 8 weeks (Figure 2).

b) What do BESS members consider to be predictive factors determining a successful return to work after an arthroscopic supraspinatus repair. Does the response vary according to profession?

ROM as a predictive factor to a successful return to work after arthroscopic SS repair was considered moderate (32\% rank 3) to increasingly relevant (32\% rank 4) and very important by both professions ( $32 \%$ rank 5 ) with no sig diff between professions $\mathrm{p}=0.16$ (Figure 3).

Evidence of tendon healing on radiology as a predictive factor to a successful return to work after arthroscopic SS repair was ranked significantly differently by each profession $(\mathrm{p}=0.03)$. Physiotherapists rated it as moderately relevant at $58 \%$ and surgeons rated it as not important at $61 \%$ (Figure 4 ).

Functional outcome measure scores as a predictive factor to a successful return to work after arthroscopic SS repair were considered very important by both professions $(65 \%)$ with no sig diff between professions $\mathrm{p}=0.65$. The pie chart is representative of the type of functional outcome scores implemented by BESS members (Figure 5). 


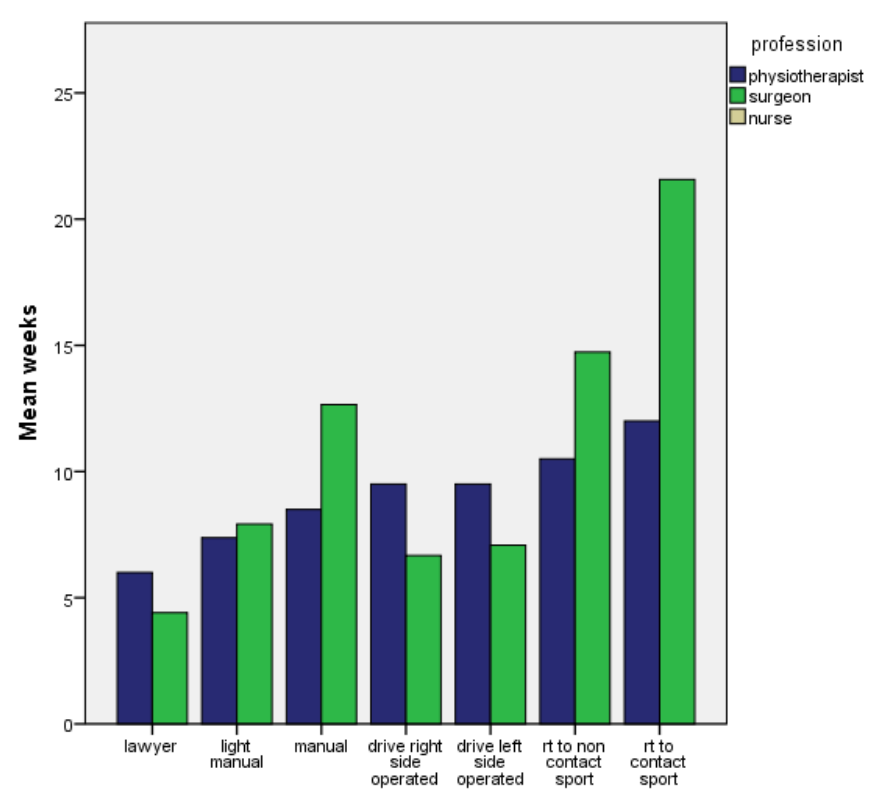

Figure 2. Return to sports and work recommendation by surgeons Vs physiotherapist

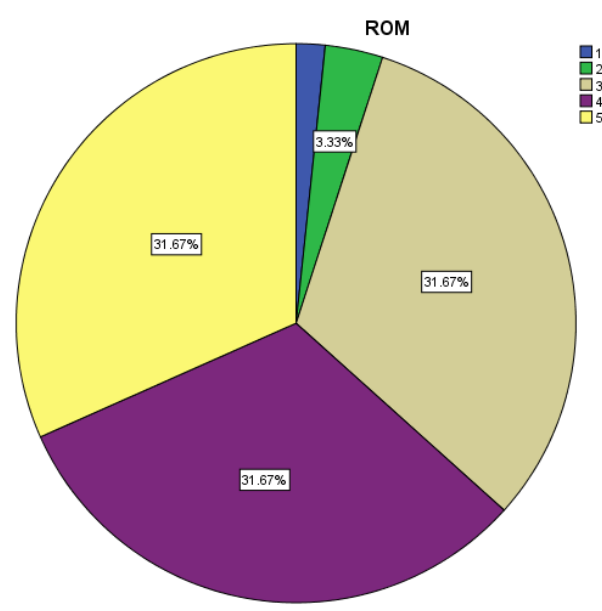

Figure 3. Shoulder range of motion
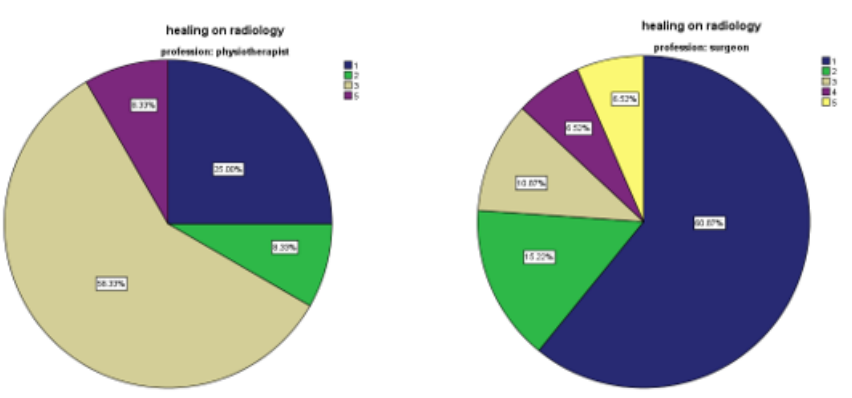

Figure 4. Tendon healing

Patient self-reported outcomes as a predictive factor to a successful return to work after arthroscopic SS repair was considered very important by both professions ( $54 \%$ rank $5 ; 29 \%$ ranked 4 ) with no sig diff between professions $\mathrm{p}=0.12$ (Figure 6).

Patient expectations as a predictive factor to a successful return to work after arthroscopic SS repair was considered moderate $(25 \%$ rank 3 ) to increasingly relevant (44\% rank 4 ) and very important by both professions (29\% rank 5) with no sig diff in ranking between professions $\mathrm{p}=0.42$ (Figure 7).

\section{Other factors for predictive RTW (Free text)}

Pain, psychological profile, job satisfaction, and patient compliance.

c) Role of special orthopedic strength/integrity tests: We hoped to evaluate the response of BESS members to assess if they considered special orthopedic strength tests of value whether these could be a predicative factor in successful return to work. However, due to the nature of the way the question was formatted only a qualitative analysis is possible for this and it was not possible to evaluate ranking. From the total number of participants (31\% missing data), 17 (27\%) responded that this is not predictive and do not test it, 3 stated it to be moderately predictive, 1 stated it is very predictive, $26(42 \%)$ responded with the type of test they would use from this it was deducted that they may consider it relevant but how relevant that cannot be assumed.

d) Percentages of BESS member who liaise with occupational health (Figure 8) and the patient GP (Figure 9)?

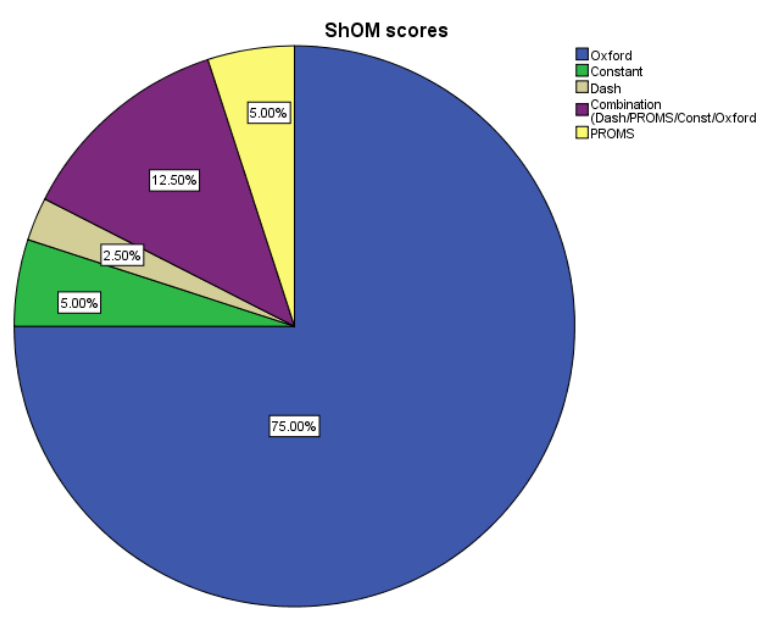

Figure 5. Shoulder functional score

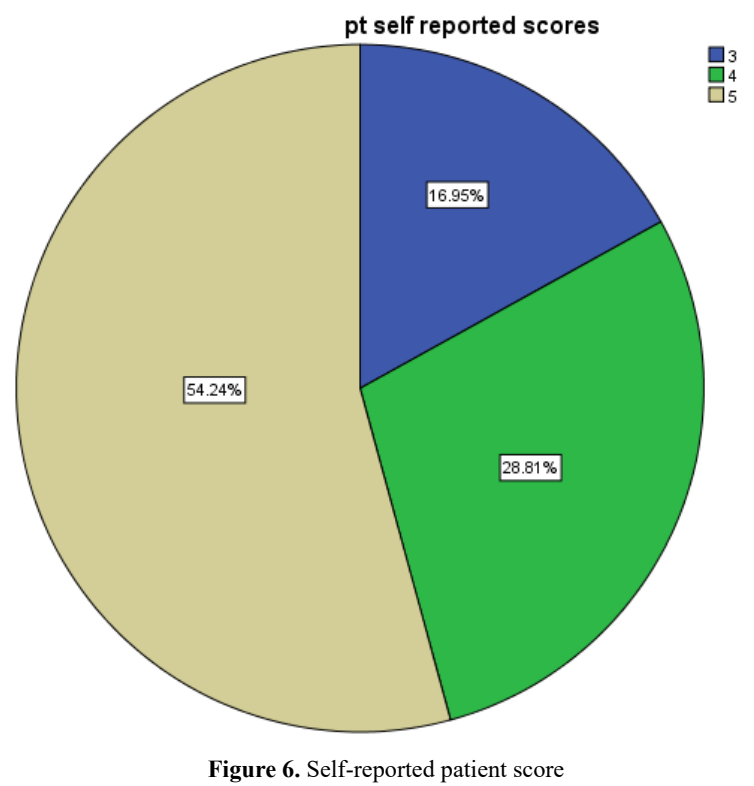

Figure 6. Self-reported patient score 


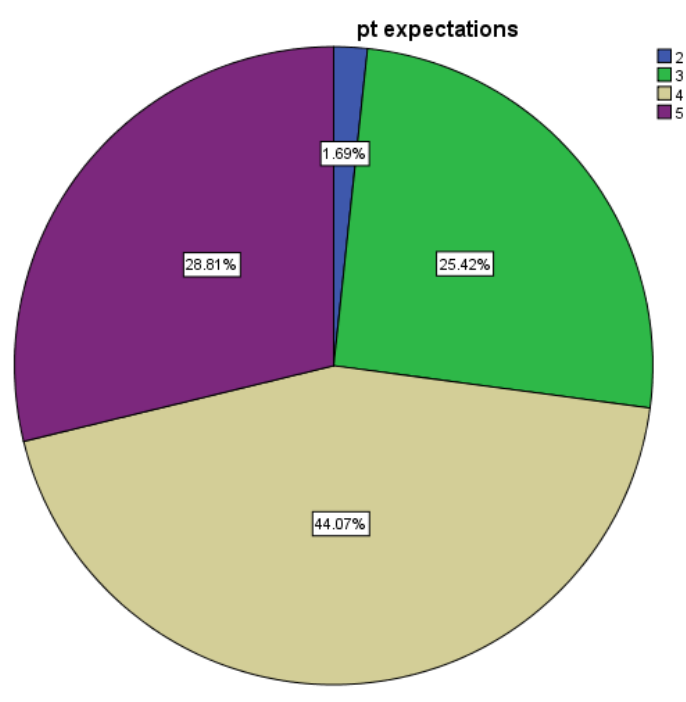

Figure 7. Patient expectation

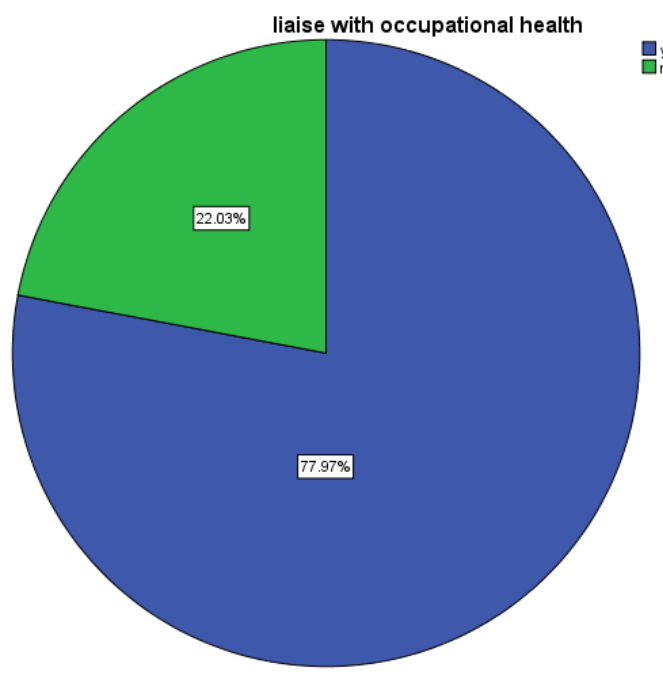

Figure 8. Liaise with Occupational Health

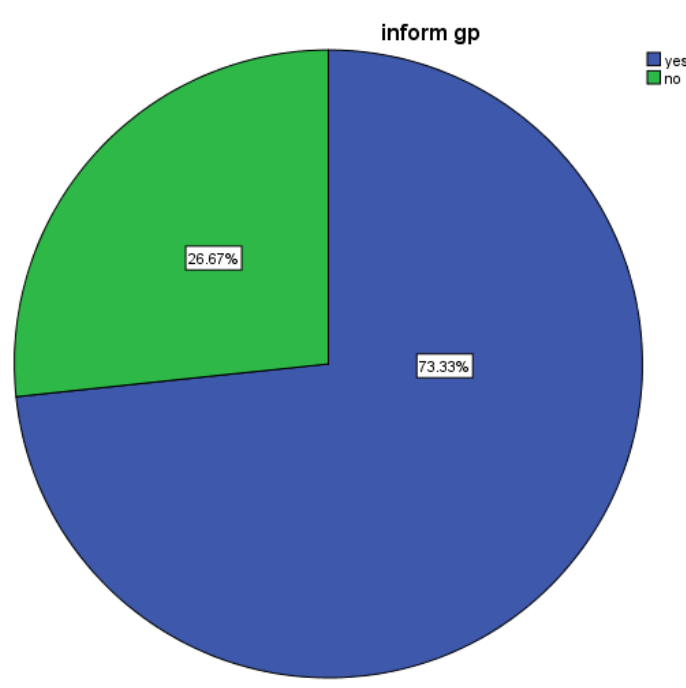

Figure 9. Liaise with patient GP
Further Statistical analysis of responses to cases given to evaluate:

i. if age was a criteria determinizing time of immobilization after $\mathrm{RC}$ repair

ii. to assess for internal consistency in responses using tear size as a factor

Comparative statistics (Wilcoxon signed ranks test) between responses with age as a dependent variable and size of tear as the independent variable were run to determine if age was used as a factor in guiding time of immobilization after RC repair. However, neither collectively or as separate professions did the respondents differ their responses using age as a criterion with all $\mathrm{p}$ values exceeding 0.05 .

Since tear size was ranked as very relvant (5) by $40 \%$ of both professions when considering immobilisation periods after Ss arthroscopic repair with no sig diff in ranking between professions $(\mathrm{p}=0.06)$ further statistical analysis (repeated ANOVA) was done to assess for internal consistency in responses by respondents using tear size as a factor. In the case of the 60 year old patient a repeated measures ANOVA with a Greenhouse-Gesser correction determined that mean weeks of immobilisation differed statistically between groups $(\mathrm{F}(1.75,102.97)=21.09, \mathrm{p}=0.01)$ of different tear size (Figure 10). Post hoc tests using Bonferroni correction revealed significant differences $(\mathrm{p}=0.01)$ in mean weeks of immobilisation between all three groups (3cm tear; $3-5 \mathrm{~cm}$ tear and more than $5 \mathrm{~cm}$ tear).

In the case of the 45 year old patient a repeated measures ANOVA with a Greenhouse-Gesser correction determined that mean weeks of immobilisation differed statistically between groups $(\mathrm{F}(1.81,103.29)=23.56, \mathrm{p}=0.01)$ of different tear size (Figure 11). Post hoc tests using Bonferroni correction revealed significant differences $(\mathrm{p}=0.01)$ in mean weeks of immobilisation between all three groups ( $3 \mathrm{~cm}$ tear; $3-5 \mathrm{~cm}$ tear and more than $5 \mathrm{~cm}$ tear).

\section{Discussion}

The current study, to our knowledge, the only study to explore return to work recommendations post rotator cuff surgery by the surgeons and PT's in the UK. The response was $8.27 \%$ of total BESS

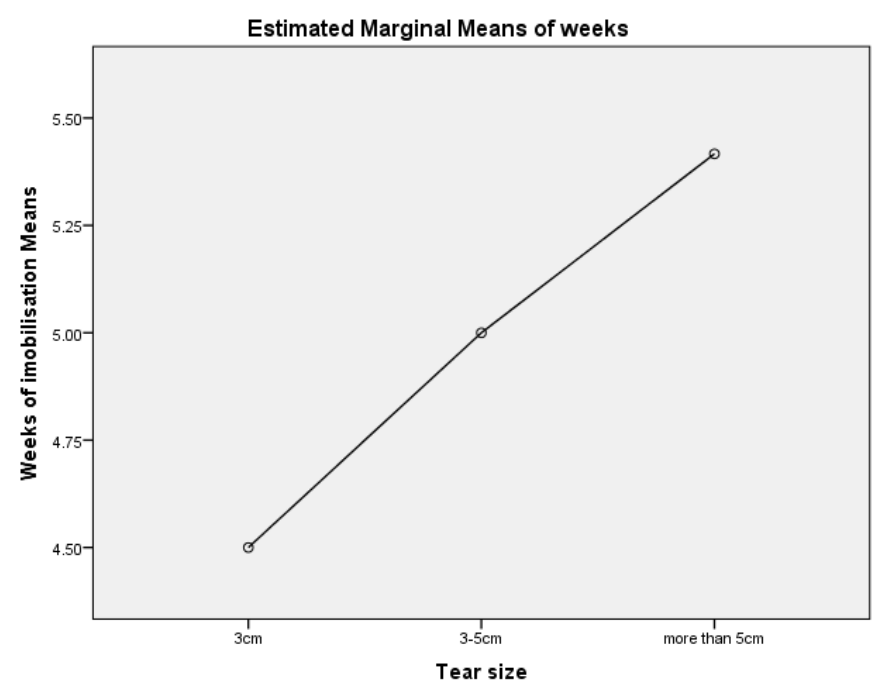

Figure 10. Estimated marginal means of weeks of immobilisation periods according to tear size in a 60 -year-old patient 


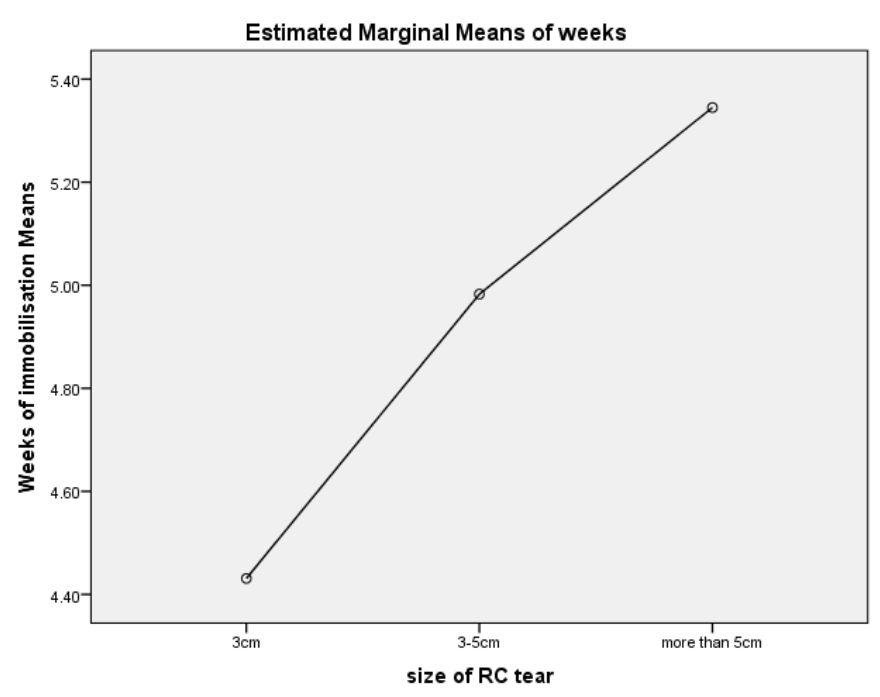

Figure 11. Estimated marginal means of weeks of immobilisation periods according to tear size in a 45 -year-old patient

members which is a low response rate this may be attributed to lack of familiarity with the subject of occupational health. Appropriate return to work recommendations post-surgery is vital not only for the patient but also to the employers considering that musculoskeletal workrelated problems accounts for the second most common cause for the loss of time from work in the UK [23]. In our study although there was variation in the recommendations between the surgeons and the PT's this was expected, return to work recommendation being a complex process which depends on multiple variables [24]. Hence this study not only explored the current practice and advice given to patients about RTW, but it also investigated the consensus on key predictive factors for successful phased or full return to work following arthroscopic supraspinatus repair surgery.

Although previous studies reported a consensus among the $93 \%$ of the respondents (PT and surgeon) supporting immobilization post rotator cuff arthroscopy [25], the participants in our study, on the contrary, believed immobilization post-surgery as 'not relevant' $(85 \%$ of the surgeons and $35 \%$ physiotherapist) and only a minority of the therapists (29\%) leaned towards being relvant in the recovery process. With regards to the actual RTW, there was a substantial disagreement between the time frames given by the surgeons when compared to the PT's for manual and light work. RTW time frames are becoming increasingly important to patients not only for the impact it has on their health-related quality of life, but for the type of financial benefits they are entitled to (UK citizens), i.e. Statutory Sick Pay (SSP) or Employment and Support Allowance (ESA) and Incapacity Benefits (IB).

Interestingly, PT's had more inclination for evidence of healing using post op radiological imaging as one of the factors to influence the return to work than the surgeons. However, several researchers in the past has cautioned against the presentation of the tendon on postoperative imaging finding as the interpretation of such imaging requires scrupulous correlation with symptoms and clinical outcomes [26,27].

Age factor in relation to immobilization post-surgery was also investigated in our study and in line with previous studies, age at the time of operation was considered as one of the factors in prescribing immobilization; perhaps the longer immobilization is being placed as a caution to prevent re-tear of the tendon [28]. Furthermore, tendon healing was not considered as among the top priorities for the PT's and surgeons in our study when determining the immobilization period, which we find interesting as the impact of early versus late mobilization and the related complications [29] has always been debated. However, this thought process might be due to the fact that evidence is overwhelming leaning towards no major difference between immobilization and early mobilization on tendon healing [30].

Return to manual work or sports recommendation also differed between the PT's and the surgeons, with return to manual work by 3 weeks, non-contact sport by 2 weeks and contact sport by 8 weeks. Unfortunately we are not aware of any published results on the return to sports post rotator cuff surgery and hence it is difficult to draw any comparison however, the vast difference between the PT and surgeons time frame can be detrimental for patients and there is an urgent need for a universal consensus to be reached.

Range of motion and functional outcome measures were reported as important for determining return to work by both PT's and surgeons however, it was not clear from their response if they would wait for a complete movement and functional gains or consider a phased return to work. Targeted approach to return to work is essential for both patients and employers to maintain a smooth workflow process as individuals can safely return to work with less functional gains and progress to more demanding work as their condition progresses. We anticipate that there is a knowledge gap among healthcare professionals about the key phases in the return to work process i.e., "off work," "work re-entry," "retention," and "advancement" [31] and hence the delay in facilitating RTW process. However, on the positive note, majority of the participants in our study reported using occupational health professional's expertise in aiding return to work and this can help in targeted return to work. Lastly, the PT's and surgeons agreed that the special orthopaedic tests were not reliable in predicting return to work or recovery post-surgery which is interesting as special orthopaedic tests for shoulder has been a topic of debate between the researchers for a long time now [32,33].

\section{Conclusion}

This is the first survey in the UK to explore the views of surgeons and PTs about their patient's return to work, driving and sports, and in relation to the factors that determine the appropriate immobilisation period, after arthroscopic supraspinatus repair. Responses highlight the potential for wide variability in the advice given to patients. In the context of contemporary literature, it might be suggested that the current advice with regards to return to work after supraspinatus surgery is not evidenced based. This study highlights the need for standardisation of practices in relation to return to work, driving and sports, and in relation to the factors that should be considered in determining an appropriate period of immobilisation.

Further high-quality research evaluating more robust advice is needed with patient and public involvement, to develop evidencedbased guidelines for recovery after supraspinatus repair surgery.

\section{Clinical Message}

- First study in UK to explore the views of surgeons and PT's about patient's return to work, driving and sports in relation to appropriate immobilisation period, and highlights the need for standardisation of practices.

- current advice with regards to return to work after supraspinatus surgery is not evidenced based 
- High-quality research needed with patient and public involvement, to develop evidenced-based guidelines

\section{Limitations}

Although we received a reasonable number of responses from specialist group in a period of 4 weeks, it was only $8.27 \%$ of the BESS members. This may be due to unfamiliar topic of return to work after single tendon repair. This is likely to represent only a small proportion of Physiotherapists and Surgeons involved in providing return to work advice. Furthermore, we did provide open space in the survey for qualitative data collection of clinicians expert views, opinions, and feedback with regards to survey, some clinicians may have not utilised that opportunity due to time constrain.

\section{References}

1. Mitchell C, Adebajo A, Hay E, Carr A (2005) Shoulder pain: diagnosis and management in primary care. BMJ: British Medical Journal 331: 1124-1128. [Crossref]

2. Urwin M, Symmons D, Allison T, Brammah T, Busby H, et al. (1998) Estimating the burden of musculoskeletal disorders in the community: the comparative prevalence of symptoms at different anatomical sites, and the relation to social deprivation. Ann Rheum Dis 57: 649-655. [Crossref]

3. Teunis T, Lubberts B, Reilly BT, Ring D (2014) A systematic review and pooled analysis of the prevalence of rotator cuff disease with increasing age. J Shoulder Elbow Surg 23: 1913-1921. [Crossref]

4. Kaplan LD, Flanigan DC, Norwig J, Jost P, Bradley J (2005) Prevalence and variance of shoulder injuries in elite collegiate football players. Am J Sports Med 33: 1142-1146. [Crossref]

5. Paloneva J, Lepola V, Äärimaa V, Joukainen A, Ylinen J, et al. (2015) Increasing incidence of rotator cuff repairs-A nationwide registry study in Finland. BMC Musculoskelet Disord 16: 189. [Crossref]

6. Barnes J, Dunkley A, Johnson DP (2009) Diagnosing shoulder pain. The Practitioner 253: 26-31.

7. Carr AJ, Cooper CD, Campbell MK, Rees JL, Moser J, et al. (2015) Clinical effectiveness and cost-effectiveness of open and arthroscopic rotator cuff repair [the UK Rotator Cuff Surgery (UKUFF) randomised trial]. Health Technology Assessment. [Crossref]

8. Oh LS, Wolf BR, Hall MP, Levy BA, Marx RG (2007) Indications for rotator cuff repair: a systematic review. Clin Orthop Relat Res 455: 52-63. [Crossref]

9. Ellman HA, Kay SP (1991) Arthroscopic subacromial decompression for chronic impingement. Two-to five-year results. J Bone Joint Surg Br 73: 395-398. [Crossref]

10. Robinson PM, Doll HA, Roy BR (2011) Treating the torn rotator cuff: current practice in the UK. The Ann R Coll Surg Engl 93: 532-536. [Crossref]

11. Dickerson CR, Meszaros KA, Cudlip AC, Chopp-Hurley JN, Langenderfer JE (2015) The influence of cycle time on shoulder fatigue responses for a fixed total overhead workload. J Biomech 48: 2911-2918. [Crossref]

12. Linaker CH, Walker-Bone K (2015) Shoulder disorders and occupation. Best Pract Res Clin Rheumatol 29: 405-423. [Crossref]

13. Miranda H, Viikari-Juntura E, Martikainen R, Takala EP, Riihimäki H (2001) A prospective study of work-related factors and physical exercise as predictors of shoulder pain. Occup Environ Med 58: 528-534. [Crossref]

14. http://www.hse.gov.uk/statistics/causdis/musculoskeletal/msd.pdf.

15. Warner JJ, Tétreault P, Lehtinen J, Zurakowski D (2005) Arthroscopic versus mini-open rotator cuff repair: a cohort comparison study. Arthroscopy 21: 328-332. [Crossref]
16. Klepps S, Bishop J, Lin J, Cahlon O, Strauss A, et al. (2004) Prospective evaluation of the effect of rotator cuff integrity on the outcome of open rotator cuff repairs. Am J Sports Med 32: 1716-1722. [Crossref]

17. Baysal D, Balyk R, Otto D, Luciak-Corea C, Beaupre L (2005) Functional outcome and health-related quality of life after surgical repair of full-thickness rotator cuff tear using a mini-open technique. Am J Sports Med 33: 1346-1355. [Crossref]

18. Keener JD, Galatz LM, Stobbs-Cucchi G, Patton R, Yamaguchi K (2014) Rehabilitation following arthroscopic rotator cuff repair: a prospective randomized trial of immobilization compared with early motion. J Bone Joint Surg Am 96: 11-19. [Crossref]

19. Kjær BH, Magnusson SP, Warming S, Henriksen M, Krogsgaard MR, et al. (2018) Progressive early passive and active exercise therapy after surgical rotator cuff repairstudy protocol for a randomized controlled trial (the CUT-N-MOVE trial). Trials 19: 470. [Crossref]

20. Cancelliere C, Donovan J, Stochkendahl MJ, Biscardi M, Ammendolia C, et al. (2016) Factors affecting return to work after injury or illness: best evidence synthesis of systematic reviews. Chiropr Man Therap 24: 32. [Crossref]

21. Ratzon N, Schejter-Margalit T, Froom P (2005) Time to return to work and surgeons' recommendations after carpal tunnel release. Occup Med (Lond) 56: 46-50. [Crossref]

22. Clayton M, Verow P (2007) A retrospective study of return to work following surgery. Occup Med (Lond) 57: 525-531. [Crossref]

23. Ingram M, Symmons DP (2018) The burden of musculoskeletal conditions. Medicine 46: $152-155$.

24. Krause N, Frank JW, Dasinger LK, Sullivan TJ, Sinclair SJ (2001) Determinant of duration of disability and return-to-work after work-related injury and illness: Challenges for future research. Am J Ind Med 40: 464-484. [Crossref]

25. Littlewood C, Bateman M (2015) Rehabilitation following rotator cuff repair: a survey of current UK practice. Shoulder Elbow 7: 193-204. [Crossref]

26. Lafosse L, Jost B, Reiland Y, Audebert S, Toussaint B, et al. (2007) Structural integrity and clinical outcomes after arthroscopic repair of isolated subscapularis tears. J Bone Joint Surg Am 89: 1184-1193. [Crossref]

27. Spielmann AL, Forster BB, Kokan P, Hawkins RH, Janzen DL (1999) Shoulder after rotator cuff repair: MR imaging findings in asymptomatic individuals-initial experience. Radiology 213: 705-708. [Crossref]

28. Robinson PM, Wilson J, Dalal S, Parker RA, Norburn P, et al. (2013) Rotator cuff repair in patients over 70 years of age: early outcomes and risk factors associated with re-tear. Bone Joint J 95: 199-205. [Crossref]

29. Parsons BO, Gruson KI, Chen DD, Harrison AK, Gladstone J, et al. (2010) Does slower rehabilitation after arthroscopic rotator cuff repair lead to long-term stiffness?. $J$ Shoulder Elbow Surg 19: 1034-1039. [Crossref]

30. Shen C, Tang ZH, Hu JZ, Zou GY, Xiao RC, et al. (2014) Does immobilization after arthroscopic rotator cuff repair increase tendon healing? A systematic review and metaanalysis. Arch Orthop Trauma Surg 134: 1279-1285. [Crossref]

31. Young AE, Roessler RT, Wasiak R, McPherson KM, Van Poppel MN, et al. (2005) A developmental conceptualization of return to work. J Occup Rehabil 15: 557-568. [Crossref]

32. Cadogan A, Laslett M, Hing W, McNair P, Williams M (2011) Interexaminer reliability of orthopaedic special tests used in the assessment of shoulder pain. Man Ther 16 131-135. [Crossref]

33. Tennent TD, Beach WR, Meyers JF (2003) A review of the special tests associated with shoulder examination: part II: laxity, instability, and superior labral anterior and posterior (SLAP) lesions. Am J Sports Med 31: 301-307. [Crossref]

Copyright: (C2020 Rai J. This is an open-access article distributed under the terms of the Creative Commons Attribution License, which permits unrestricted use, distribution, and reproduction in any medium, provided the original author and source are credited. 